\title{
De los zombis a los walkers. EI despertar de la economía fandom
}

\section{Johanna Montauban}

Universidad de Lima

johannamontauban@gmail.com

RESUMEN

El sistema de medios masivo, que producía contenido para audiencias masivas, se encuentra en crisis. El uso que los públicos dan a las diversas plataformas digitales ha alterado la relación entre ellos $y$ los medios. Ahora ya no solo son los medios los que producen y distribuyen los contenidos, sino que se vuelven más dependientes de sus públicos para poder circularlos.

Este artículo relaciona los discursos de la serie televisiva The Walking Dead (TWD) con las prácticas sociales, culturales y económicas del fandom The Walking Dead Perú (TWD-Perú). Aborda la producción cultural colaborativa que realizan en el entorno mediático transmedia, en el que las tecnologías digitales facilitan la creación, distribución y manipulación de contenidos. El grupo nace con la creación de la página de Facebook; desde ahi se desarrollan vínculos motivados por la afición a dicha serie que se expanden en los eventos que producen, transformando el consumo debido a la interacción que estimulan. De esta manera, generan valor mediante la circulación extendida de los contenidos, es decir, desarrollan redes económicas alternativas, a las que denomino economía fandom.

Palabras clave: fandoms, transmedia, economía fandom, producción cultural colaborativa, The Walking Dead. 


\section{From the zombies to the walkers. The awakening of the fandom economy}

ABSTRACT

The traditional media system that produced content for certain audiences that consumed it is in crisis. The use that audiences give to various digital platforms has altered the relationship between them and the media. Now it is not only the media that produce and distribute the contents, but they also become more dependent on their public to circulate them.

This article relates the speeches of the television series The Walking Dead (TWD) with the social, cultural and economic practices of the fandom The Walking Dead Peru (TWD-Peru). It addresses the collaborative cultural production that they perform in the transmedia media environment, in which digital technologies facilitate the creation, distribution and manipulation of content. The group was born with the creation of the Facebook page, from there it developed links motivated by the fans of the series that expand in the events they produce, transforming consumption due to the interaction they stimulate. In this way, they generate value through the extended circulation of content, that is, they develop alternative economic networks that I call the fandom economy.

Keywords: fandoms, transmedia, fandom economy, participatory culture, The Walking Dead. 


\section{INTRODUCCIÓN}

«En un mundo gobernado por los muertos, nos vemos obligados finalmente a comenzar a vivir» ${ }^{1}$. Esta frase promocional de la serie televisiva The Walking Dead (TWD) resulta significativa en un entorno de cambios acelerados, digitalización de la cotidianidad y obsolescencias programadas, que marca el surgimiento del grupo The Walking Dead-Perú (TWD-Perú). A lo largo del texto, exploro cómo se crean redes sociales a partir de la extensión del consumo, gracias al uso de las tecnologías digitales e internet. Ellos han aprovechado las transformaciones de la ecología mediática para desarrollar una producción cultural colaborativa vinculada con la creación de contenidos y experiencias de entretenimiento que amplían el contenido original. Esta serie de intercambios —o economía fandom - les ha traído beneficios que abordaré en las siguientes líneas.

TWD-Perú nace el 18 de octubre de 2011 con la creación de la página en Facebook $^{2}$. A diferencia de los perfiles personales, las páginas de Facebook pueden ser de acceso público, lo cual impulsa la creación de colectivos de usuarios aglutinados por intereses comunes. Esta plataforma permite que las personas puedan compartir contenidos, comentar lo que otros publican, llevar a cabo conversaciones colectivas y descentralizadas, adherir a más miembros, mantenerse conectados, organizar y coordinar eventos, etc. De esta manera, las distancias parecen acortarse y el tiempo se vuelve más flexible. Asimismo, contribuye a la institucionalización del fandom, es decir, a la transformación de esta práctica inorgánica hacia una situación organizada, principalmente porque permite conectar a personas. En el año 2019, TWD-Perú superó los 170000 seguidores, la página no oficial de la serie en Sudamérica más numerosa después de la de Brasil, que cuenta con dos millones. Este crecimiento no se limita a la

«In a world ruled by the dead, we are forced to finally start living».

The Walking Dead-Perú: https://www.facebook.com/TheWalkingDeadFanPagePeru?fref=ts 
cantidad de seguidores, pues han logrado trascender la red y desarrollar una serie de experiencias de entretenimiento paralelas a la serie que han incrementado su productividad y capacidad de gestión.

Me concentro en lo que he clasificado como los miembros activos de TWDPerú, o sea, los que participan en la producción de los eventos y el manejo de la cuenta, ya que son los que articulan las actividades, mientras que los seguidores de la página y los que asisten a las actividades como público tienen una participación más pasiva como parte del colectivo. Mis fuentes principales son Jonathan Aguilar y Mario Maldonado, debido a su capacidad de agencia, tiempo como miembros del equipo y volumen de actividad. Asimismo, recojo los testimonios de otros quince integrantes. El presente artículo forma parte de una investigación etnográfica en la que apliqué diversos métodos cualitativos a lo largo del trabajo de campo realizado por más de tres años. Efectué entrevistas en profundidad, conversaciones espontáneas en Messenger, observación participante durante los eventos por inicio, mitad y cierre de temporada3, así como en otros eventos en los que participaron como invitados. Además, analicé el contenido tanto de las publicaciones en Facebook como de la serie TWD y de lo zombi, para contextualizar y comprender las asociaciones que emergen en los discursos de los sujetos.

Es preciso mencionar que la palabra apocalipsis es entendida como sinónimo de cambio y no de fin, como una situación que impulsa a asumir retos y enfrentar obstáculos. En los personajes de la ficción lo que motiva el cambio en sus vidas es una pandemia; en el caso de los sujetos de la investigación son las performances que desencadenan el desarrollo de una red económica alternativa a partir de su afición. En otras palabras, exploro las funciones que el consumo de esta serie ha tenido en la construcción de esta «socialidad». Empleo este término en la acepción que propone Postill (2015) para referirse a la calidad social única que caracteriza una determinada práctica o interacción compartida. Es decir, las circunstancias o características que los distinguen.

Free Comic Book Day en C.C. Cyberplaza 02-03.05.2015, Comic Market en C.C. Compupalace 30-31.05.2015, Hobbie Day en C.C. Compupalace 18-19.07.2015, Weekend Dead en discoteca Céntrica del C.C. Real Plaza 02.08.2015, Fantasy Fest en C.C. Polvos Rosados 03-04.08.2015, inicio de la sexta temporada en discoteca Céntrica del C.C. Real Plaza 11.10.2015, Amazing Game, show en Centro de Convenciones de Plaza San Miguel 23-25.10.2015, Geek Fest en Jockey Club del Perú. 28.11.2015, Play Land Park en Jockey Club del Perú 19.06.201606.03.2016, inicio de la sétima temporada en la discoteca Mangos (ex Cocos) 23.10.2016, final de mitad de temporada en el pub La Bóveda, ciudad de Arequipa 11.12.2016, final de la sétima temporada en la discoteca Mangos 02.04.2017, inicio de la octava temporada Weekend Dead Lima en la discoteca Cocos 29.10.2017, final de la octava temporada Weekend Dead Lima en la discoteca Cocos 15.04.2018. 
A lo largo del texto construyo paralelos entre la serie y las situaciones sociales que describo, primero entre apocalipsis zombi y el apocalipsis del sistema de medios masivos. Así como en la ficción se propaga un virus que afecta a los seres humanos convirtiéndolos en walkers y cambiando las circunstancias del entorno, el uso de las tecnologías digitales por los usuarios ha alterado el sistema de medios masivos. En particular, abordo las transformaciones a partir de las acciones de los fans o del efecto del «virus fandom», pues resulta representativo para explicar el escenario mediático que se distingue. Además, comparo el discurso apocalíptico de la serie televisiva y el discurso emprendedor, que uso para describir la actitud de los miembros de TWD-Perú respecto de sus actividades como productores culturales. Por un lado, los protagonistas de la serie se las ingenian para sobrevivir en un mundo diferente al de antes, inestable, devastado por una pandemia, y por otro, los propios fans, que también se esfuerzan por afrontar los retos y contratiempos que se presentan en sus actividades, que habiendo empezado como un pasatiempo, terminan siendo productivas económica y sobre todo socialmente. Así como los protagonistas deben sobrevivir al complejo entorno postapocalíptico, los miembros de TWD-Perú deben mantenerse en el competitivo entorno de la producción de contenidos de entretenimiento alterado por el uso de plataformas digitales.

El drama televisivo estadounidense TWD, estrenado el 31 de octubre de 2010, está inspirado en el cómic del mismo nombre. Tiene como protagonista a un grupo de sobrevivientes que luchan por subsistir en medio de un escenario devastado por una pandemia que convierte a los seres humanos en walkers, entes sin voluntad ni conciencia. Los zombis adoptan este nombre -inventado por Robert Kirkman, creador de la historia - como estrategia para diferenciarse de otras sagas del subgénero. La serie, ambientada en la actualidad estadounidense, empieza cuando Rick se despierta en un hospital tras haber estado en coma y encuentra un escenario postapocalíptico en el que solo quedan indicios de la civilización precedente. En su trayecto logra encontrar a su familia, y junto a otras personas, forma un grupo denominado Los sobrevivientes de Atlanta, que componen el núcleo de protagonistas de la trama. Los capítulos abordan los desafíos que implica enfrentarse tanto a los walkers como, sobre todo, a otros grupos humanos que luchan por sobrevivir e imponerse. Lo zombi es un motivo para aproximarse a los conflictos entre los personajes y los dilemas de un escenario incierto, de escasez, en el que la inseguridad se vuelve ubicua y cuya única certeza es el cambio que exige la movilidad constante. «El mundo ya no es lo que solía ser» es una expresión reiterada en diversos capítulos, que exhorta a esforzarse para lograr una existencia social parcialmente digna, con normas y valores compartidos. 
A diferencia de los zombis clásicos como los de The night of the living dead, que son muertos que salen de sus tumbas, los walkers representan un estado latente en los sobrevivientes, puesto que todos son portadores del virus que desencadena la pandemia. Es decir, los sobrevivientes son walkers en potencia. Mientras que el zombi era algo exótico, externo, el otro monstruoso al que los humanos debían encarar, ahora el monstruo se inscribe en el propio ser humano. Esto trae un giro importante que coincidentemente marca un cambio en el contexto sociocultural. En el escenario global que alimenta la ficción de TWD, el desplazamiento es hacia el individuo como único responsable de su destino. La sobrevivencia depende de las acciones que tomen, de los riesgos que asuman y de la manera de adaptarse a los cambios que el propio contexto apremia. El propio ser humano puede convertirse en héroe o en un potencial peligro para los demás, pues, al igual que el walker, termina matando, sometiendo a los demás, deshumanizándose. Entonces, la lucha de los protagonistas no solo es contra los caminantes sino también contra otros grupos humanos que los obligan a desplazarse y consigo mismos para no perder su humanidad.

La serie advierte el peligro que puede causar la alteración de la naturaleza humana a partir de la proliferación de un virus que se entrevé fue desarrollado en un laboratorio. Este desencadena una vuelta hacia el nomadismo y la animalidad del ser humano. En efecto, los personajes pierden rasgos culturales previos, su identidad, y a medida que avanzan las temporadas la diferencia con los walkers se desvirtúa. El walker recuerda que «todos somos caníbales» (Strauss, 2015); sin embargo, podemos evitarlo y eso es cultura. Todos podemos 'comernos' los unos a los otros mediante la explotación alienante, como se observa en otros grupos de sobrevivientes, por ejemplo en Los Salvadores. Negan, su líder, es un psicópata que tiene coaccionados a sus súbditos, a quienes ha despojado de su identidad, de su individualidad y hasta de su nombre, llegando al extremo de obligarlos a presentarse con la frase: «Yo soy Negan».

Por eso, la lucha de los sobrevivientes de Atlanta es también un intento de restablecer un orden político y social digno. Abrirse paso junto a otras personas intentando mantenerse unidos es el arma principal para mantener cierta humanidad y evitar convertirse en walkers. Podría decirse que los walkers también están juntos por un objetivo: devorar a los seres humanos que quedan, pero la diferencia radica en que los humanos son capaces de elaborar estrategias, plantear reglas y trabajar como colectivo, pues pueden razonar en conjunto, mientras que los otros son entes guiados por el instinto y no por la reflexión. 
La correspondencia con preocupaciones sociales contemporáneas es uno de los atractivos de la serie y, en general, del subgénero. Cabe mencionar que las tramas sobre zombis suelen tener como subtexto alguna problemática sociocultural. Por ejemplo, mientras que los zombis alcanzan popularidad como iconos críticos de una cultura de masas y de consumo alienante, los walkers se inscriben en un entorno cambiante caracterizado por el «hiperconsumo» (Lipovetsky y Sebastien, 2014). Los autores señalan que vivimos en una época de hiperindividualización y desalienación del consumo. Así, mientras que anteriormente el consumo servía para ostentar o conseguir un estatus, ahora se buscan otras ganancias, como el placer, la emoción y las experiencias diferentes. En el plano mediático, este entorno implica la transformación en la producción, circulación y consumo de contenidos mediáticos.

\section{EL APOCALIPSIS DEL SISTEMA DE MEDIOS MASIVOS A TRAVÉS DEL FANDOM}

Con la explosión digital, tanto los medios como su relación con las audiencias vienen transformándose. Dicho de otro modo, la interrelación entre los medios, la tecnología y las prácticas cotidianas viene transitando por una serie de cambios. El sistema de medios masivos, en que un grupo reducido de productores o broadcasters creaba contenido específico para cada medio (la televisión, la radio, el cine y la prensa) y se dirigían a grandes audiencias que ejercían un consumo tradicional, se encuentra en crisis ante un sistema mediático transmedia, cuyas características fundamentales son la diseminación de relatos a través de muchos medios y la participación de los públicos para su circulación y expansión. De esta manera, satisfacen también esa necesidad del hiperconsumidor de experiencias emocionales. Por ello conviene analizar a los fans, pues constituyen una pieza clave para comprender la «cultura participativa» (Jenkins, 2010) en la era digital, en la que incrementa su agencia, o sea su capacidad para actuar, desenvolverse e intervenir.

Para John Sullivan (2013), existen dos aspectos característicos en la cultura fan: el interpretativo y el social. El aspecto interpretativo está relacionado con el hecho de que los fans analizan a profundidad los significados de los textos mediáticos, velan por proteger el canon original contra alteraciones que no lo respeten y producen contenidos paralelos a partir de los temas, situaciones o personajes. Los fans siempre están en movimiento, avanzando hacia otros textos, apropiándoselos y construyendo nuevos significados, lo cual les ha valido el apelativo de 
nómadas, pues no necesariamente tienen un interés único en determinada serie, sino que establecen conexiones intertextuales entre diversos materiales de los medios de comunicación. El aspecto social está vinculado con la formación de grupos que se gestan a partir de la necesidad de compartir estos conocimientos e intereses comunes en torno a productos de la cultura popular.

Si bien los fans siempre han desarrollado contenidos paralelos a la obra original, como fan fiction, fan art o fansubbing, con la explosión de los medios digitales estas creaciones que circulan por la red como anexos del producto original se amplían tanto en volumen (cantidad de material producido) e intervención (posibilidad de creación a partir del material original) como en alcance (posibilidad de ser compartidos por miles de personas en diferentes lugares). En otras palabras, el uso de la tecnología por los fans ha potenciado la participación y redistribución de los contenidos mediáticos, lo que implica una experiencia con el producto diferente y definitivamente más dinámica.

En efecto, una de las características más resaltantes de este entorno transmedia es la posibilidad que tienen las personas de transformar y performar con los contenidos de los medios. Pueden crear avatares, hacer memes, realizar ediciones caseras con los contenidos, compartir información en múltiples plataformas, entre otras posibilidades cada día más variadas gracias a diversos factores, como la digitalización de la tecnología audiovisual, su abaratamiento, la extensión de internet, etc.

De esta manera, los consumidores se convierten en productores o modeladores de contenidos o, como algunos tienen a bien llamar, en prosumers, término acuñado por primera vez por Alvin Toffler (1995) a partir de la combinación de las palabras en inglés producer (productor) y consumer (consumidor). Por ejemplo, en el caso de algunos fans comienzan siendo seguidores ávidos de los contenidos y luego toman esos materiales para editarlos, mezclarlos, y así crear nuevos contenidos.

La importancia de las creaciones que hacen los fans no se restringe a la promoción: puede repercutir incluso en las decisiones sobre los giros en el guion o la continuidad de ciertos personajes. Por citar un ejemplo, en la novena temporada de TWD apareció un perrito que se hizo compañero de uno de los protagonistas. Los fans, temerosos de que los guionistas decidieran matarlo como ya lo han hecho con otros personajes entrañables, desarrollaron una campaña para salvarle la vida a través de la página Care2 Petitions llamada: «Por favor, no maten al perro en The Walking Dead», que ha llegado a recolectar más de 45000 firmas alrededor del mundo. Según lo indicado por la showrunner de la serie, no lo harán. 
Si bien esta iniciativa no se originó en el Perú, pudo empezar en cualquier lugar, en cualquier momento y por cualquier persona, pues las plataformas digitales desvanecen los límites del espacio y tiempo que enmarcaban el consumo masivo. Lipovetsky afirma que «ahora nos vemos en un continuo consumista cósmico, desincronizado e hiperindividualista» (2007, p. 10). El consumo activo o el «hiperconsumo», como lo denomina el autor, es paradójico, porque es emocional, sensorial, pero reflexivo. El hiperconsumidor es informado, busca circuitos alternativos, compara y exige. Así, el autor observa un cambio de un consumidor homogéneo, masivo, a uno emocional, atomizado, que amplía sus opciones y está preocupado por su entorno. Siguiendo esa línea, encontramos conexiones entre este nuevo consumidor, los fans y el sistema mediático transmedia. Sin embargo, el filósofo advierte que, mientras más poder tiene el hiperconsumidor, más influencia obtiene el mercado, y eso se comprueba en las megafusiones o en la concentración de medios en el caso particular que se aborda.

En este giro hacia la demanda, puede situarse la producción de contenidos que realiza el consumidor como una forma de ampliar su experiencia de consumo. Al recrear los productos y compartirlos, transforma la organización de la oferta y las prácticas cotidianas. Lee Siegel (2008) critica la producción que hacen los consumidores a partir de productos de la industria o de situaciones banales. Cuestiona esta forma de «autoexpresión», pues conlleva a una popularidad que no es auténtica, ni meritoria, ni permanente, sino más bien por imitación, ocasional y poco loable. Incluso afirma que «acaparar la atención es ahora una fuente de ingresos $[\ldots]$ hacer lo que se siente y hacer negocio en el mercado es ahora la misma actividad» (Siegel, 2008, p. 112). Para el autor, vivimos en una época de banalización de la expresión propia, o lo que viene a ser lo mismo, la mediatización de lo banal. Sin embargo, la producción que hacen los consumidores (al menos en el caso particular que se aborda) a partir de los contenidos de los medios y la popularidad que pueden alcanzar con su actividad no es tan intrascendente como sugiere, pues en mayor o menor medida implica un acto creativo, de producción, manipulación, transformación y circulación cultural en un contexto colaborativo. Además, estas prácticas les brindan diversas recompensas no solo económicas sino también sociales, tales como la ampliación de sus redes sociales, el reconocimiento y la participación. En consonancia, Paul Booth (2010) analiza el potencial que tiene el trabajo creativo de los fans, quienes son considerados como mercancías dentro de la industria mediática, pues sus creaciones cobran valor en el mercado.

Cornel Sandvoss (2005, p. 8) elabora una clasificación de los fans acorde con su nivel de compromiso, que va en un continuo desde el consumidor, pasando 
por los entusiastas y los aficionados ocasionales, hasta el pequeño productor, personas que hacen de su actividad como fans una profesión y comercializan sus producciones. Justamente el núcleo de base de TWD-Perú encaja en esta última descripción, ya que participan en la creación de contenidos de la página, así como en de la producción y organización de los eventos. Son mucho más que fans seguidores, comentaristas o asistentes a eventos. Lejos de constituirse como actos banales, sus acciones han impactado significativamente en sus vidas.

Al hablar de la naturaleza social del fan, conviene trazar una diferencia entre la palabra fan y una palabra que cada vez adquiere mayor uso: fandom. Esta última se forma de la contracción de las palabras fan y kingdom. El origen de este término se asocia a los grupos de aficionados a la ciencia ficción o a la literatura fantástica; sin embargo, su uso se ha extendido para referirse a colectivos formados en la red motivados por su afición a determinado producto o, en general, a diversas producciones mediáticas. Mientras que los fans refieren a individuos que tienen un interés especial en una producción mediática, los fandoms se identifican como parte de un colectivo con el cual sienten un compromiso y comparten preferencias en común. Esta diferencia es crucial de cara al cambio de un sistema de medios masivos que se concentraba en alcanzar a cierto número de personas de la audiencia, a un sistema transmedia que pretende abordar o construir públicos. Daniel Dayan señala que «un público no es simplemente un espectador en plural, un total de espectadores, una suma. Es una entidad coherente cuya naturaleza es colectiva; un conjunto caracterizado por una sociabilidad compartida, una identidad compartida y cierto significado de esa identidad» (Dayan, 2005, p. 46). Bajo esta lógica, los fans se corresponden como parte de las audiencias, en contraste con los fandoms, que comparten características con los públicos. Por ello, esta palabra se vuelve más adecuada al momento de describir lo que hacen grupos como TWD-Perú.

Los fandoms son colectivos que incorporan los productos mediáticos e interconectan los textos con la cotidianidad de las personas. No deben entenderse en términos anacrónicos, como entidades discretas; por el contrario, son de composición cambiante. Se constituyen como grupos diaspóricos, disgregados alrededor del mundo, que atraviesan nuestra sociedad mediatizada. Sus miembros conforman un estilo de vida más que, contrario al estereotipo negativo, permite conectar con otras personas y ubicarse en la sociedad ante la necesidad de particularismos que surgen con la globalización. Por eso, Michel Maffesoli (2004) señala que vivimos la «tribalización del mundo postmoderno», es decir el surgimiento de microcomunidades sociales o subculturas que se articulan con 
sentimientos, emociones y experiencias por estar juntos. Nicholas Christakis y James Fowler (2010) agregan que estas se forman bajo la lógica de la red como una organización natural no impuesta desde arriba y que evoluciona orgánicamente a partir de la necesidad humana de relacionarnos.

No obstante, estas ideas también presentan limitaciones. En Digital Ethnography. Principles and Practice, Pink, Horst, Postill, Hjorth y Lewis (2015) se cuestionan términos como subcultura, comunidad o red, pues a pesar de expresar una sensación de unidad, presentan inconvenientes en la práctica para describir formaciones sociales en un contexto efímero, heterogéneo, diverso y disperso. Por eso, proponen el uso del término más neutral «mundos sociales» que describen como «dominios relativamente acotados, pero nunca herméticos, de la vida social que existen en una gran diversidad [...] Los mundos sociales nunca están aislados de otros mundos sociales, o incluso del resto de la humanidad en nuestro mundo masivamente interconectado [...] Tienden a cruzarse con otros mundos, sus fronteras no son fijas ni claras para personas internas o externas. La gente viene y se va, y los mundos aumentan y disminuyen con el tiempo». Los fandoms constituyen «mundos sociales» entendidos como «dominios relativamente acotados, pero nunca herméticos, de la vida social [...] Los mundos sociales nunca están aislados de otros mundos sociales, o incluso del resto de la humanidad en nuestro mundo masivamente interconectado [...] Tienden a cruzarse con otros mundos, sus fronteras no son fijas ni claras para personas internas o externas. La gente viene y se va, y los mundos aumentan y disminuyen con el tiempo» (Pink, Horst, Postill, Hjorth y Lewis, 2015, p. 102).

Si bien el fandom es una agrupación volátil que tiende a desaparecer (en algún momento TWD-Perú perecerá, quizá cuando la serie sea cancelada), las habilidades que desarrollan sus miembros se extienden más allá del tiempo de vida que pueda tener el grupo. Así, los conocimientos en organización de eventos, en manejo de grupos o en administración de comunidades digitales, entre otros, son permanentes y útiles en diversos espacios.

\section{NOSOTROS SOMOS THE WALKING DEAD-PERÚ}

Esta es la frase que gritan los cientos de seguidores antes de empezar un nuevo capítulo de la serie en los eventos que organiza el fandom. Para los organizadores, el lema representa una autoafirmación, una adaptación de la trama de la serie a su propia experiencia. TWD-Perú, a través de sus acciones, reedifican la cultura a partir del mainstream audiovisual, pero de un modo alternativo. Dejaron de ser 
una audiencia seguidora de una trama de zombis para constituirse en un público que propaga el «virus fandom» dentro y fuera de la red, reforzando su identidad y configurando una «socialidad».

El núcleo de base de TWD-Perú se estructura a partir del administrador de la página de Facebook, a quien se le suma el staff de producción que apoya en la realización de las actividades del grupo y el staff de zombis o performers que participan tanto en eventos propios como en activaciones donde los convocan. Jonathan Aguilar, administrador actual del sitio y productor, se unió cuando este solo tenía trescientos seguidores. Su constancia lo convirtió en el único community manager de la página desde finales de 2013. Su principal colaborador es Mario Maldonado, que es experto en las tramas de zombis y de superhéroes de Marvel y DC Cómics, lo que le ha servido para hacerse conocido entre algunos fandoms en nuestro país. En las actividades de TWD-Perú trabaja como animador, tanto por su conocimiento como porque es actor de profesión.

En líneas generales, los miembros activos de TWD-Perú se ubican como parte de un nivel socioeconómico medio. Residen con sus padres o familiares en distritos como Chorrillos, Callao, Puente Piedra, Santa Anita. Tienen educación escolar completa. Se encuentran estudiando o ya culminaron sus estudios superiores, ya sea en institutos o universidades. Otra característica común es que consideran que el desarrollo profesional pleno se relaciona con hacer lo que les apasiona. Por eso, el fandom también resulta una forma de mezclar sus estudios con su afición. Ven en el despliegue que hace el grupo una posibilidad de participación del sistema mediático. A través de sus performances ingresan desde una puerta trasera y con sus acciones dan cuenta de procesos de transformación.

Los miembros activos de TWD-Perú consumen materiales vinculados con la serie TWD y con el género zombi, pero también revisan otros productos de la cultura pop que muchas veces les sirven para generar contenidos. También se involucran en encuentros como el Free Comic Book Day, el Hobbie Day, el Fantasy Fest, el Horror Fest, entre otras reuniones que vinculan el mundo de los superhéroes, la ciencia ficción, los animes, el cine fantástico, entre otros. Son espacios donde que los fandoms cobran más visibilidad y pueden conocer las últimas novedades y compartir con los asistentes sus experiencias.

A mí organizar todo me ha dado mucha satisfacción, es el «punche». Siempre he sido fanático de los zombis y ahora yo mismo puedo sobrevivir a mi apocalipsis zombi cuando quiero. Me ha permitido conocer un montón de gente. Tener buenos contactos. Todo esto lo conocí gracias a la página. ¿Qué hubiera sido mi vida sin TWD? Sería aburrida, no vendría a eventos... Antes 
yo sabía que se organizaban eventos, pero me daba mucha vergüenza, y mira, ahora yo los organizo, y cuando veo a la gente que está así, les digo mira, ven, acércate. Me siento identificado porque yo no era una persona sociable como soy ahora (Jonathan Aguilar).

Durante el trabajo de campo las edades de los miembros del grupo fluctuaban entre 16 y 34 años. Forman parte de la generación denominada «millennials», que agrupa a personas nacidas entre las décadas de 1980 y 2000, caracterizada por su amplio uso de tecnologías digitales y su participación y compromiso con determinadas causas. Es en este sentido que dicho término los enmarca.

En Millennial Fandom (2015), Louisa Stein asocia a esta generación con el fandom, ya que comparten las mismas características: participantes activos de la cultura mediática que los rodea en lugar de meros receptores, hábiles en el uso de tecnologías digitales y orientados a la comunidad. Particularmente, los miembros activos de TWD-Perú construyen una identidad centrada en el consumo activo de la serie y en el despliegue de diversas acciones, para las cuales utilizan el espacio online para congregar a personas con intereses similares, lo que luego posibilita el encuentro offline.

Stein plantea que existe un discurso esperanzador vinculado con la posibilidad de participación y el incremento del control por la audiencia, que designa como millennial hope. Y otro discurso inquietante que llama millennial noir, que representa a esta generación como moralmente ambigua, como «piratas de textos». Esta expresión fue creada por Jenkins para explicar la complejidad de su filiación:

[El fan] construye su propia identidad y sus productos a partir de los recursos tomados prestados de los textos que ya están en circulación. Desde el principio, una descripción de la cultura de los fans debe de señalar necesariamente su estatus problemático, sus inevitables relaciones con otras formas de producción cultural y otras identidades sociales. Nadie se mueve exclusivamente dentro de una cultura de los fans, ni tampoco ésta reivindica su autosuficiencia. Esta cultura no es ni intemporal ni inmutable. Los grupos de fans se originan en respuesta a unas condiciones históricas concretas que cambian constantemente (Jenkins, 2010, pp. 12-13).

Aquí no uso esta expresión, puesto que la piratería en nuestro país no tiene una connotación fantástica o seductora; por el contrario, es una práctica perjudicial extendida asociada a la apropiación indebida y la ilegalidad. En contraste, las prácticas de TWD-Perú se basan en la ampliación a partir del original, con lo cual no solo se benefician ellos sino también la marca TWD, que adquiere circulación y promoción. 
La publicación de contenidos en la página TWD-Perú suele ser diaria durante la emisión de la temporada de la serie, con la finalidad de lograr mayor exposición en la red y volumen de seguidores que comenten, compartan y vinculen. Las actualizaciones son diversas: anuncios de eventos en los que participarán, escenas eliminadas, situaciones inéditas, parodias, tributos a los actores o avisos coyunturales de acuerdo con festividades del calendario o sucesos específicos. Facebook invita a performar constantemente, no solo a través de las pantallas sino también fuera de ellas, ya que, si no están en constante actividad, los seguidores pierden interés e, incluso, la misma plataforma los invisibiliza.

A partir de la ampliación de contenidos de la serie, generan dinámicas grupales que hacen posible el desarrollo de los eventos y la difusión de su trabajo no solo entre sus pares sino entre empresas que los contactan para que participen en diversas actividades vinculadas con su afición por los zombis. El primer evento que produjeron se llevó a cabo el 26 de mayo de 2012 en un local de la calle Berlín, en Miraflores. En la convocatoria anunciada en Facebook ya se definían como colectivo:

No somos simples individuos, somos una COMUNIDAD 4 , y esto, porque somos un grupo de personas que buscan reunirse para hablar de un tema de gusto común: The Walking Dead, sea la serie, el cómic, los juegos digitales, juegos de mesa, etc. Por ello, la primera actividad que realizaremos será una presentación de los administradores; en ella hablaremos sobre cómo se creó la página.

En los primeros encuentros, la asistencia fluctuaba entre treinta y cincuenta personas y los lugares de encuentro eran pequeños pubs o alguna de las aulas del instituto donde trabajaba Jonathan. Pero las ganas de querer hacer eventos más grandes para fans, como los que se producen en otros países, condujo a que se convirtieran en uno de los fandoms más organizados del Perú. Poco a poco el cronograma de los eventos fue aumentando y las ideas se diversificaron. Ya no solo era ver un capítulo de la serie en grupo y comentarlo, sino idear diversas actividades para el público asistente. Por ejemplo, en una oportunidad alquilaron un área de paintball donde recrearon de un escenario de enfrentamiento entre walkers y sobrevivientes, en el que estos tenían que matar con munición de paintball antes de que los alcancen a ellos. En marzo de 2014 surge la idea de hacer un tour zombi, un recorrido en el cual los sobrevivientes (participantes) intentan

4 Las mayúsculas estaban en el texto de la página de Facebook y las reproduzco exactamente. 
escapar de los zombis, a la vez que experimentan la necesidad de moverse constantemente para no morir. Para poder hacer realidad esta idea, Jonathan publicó a través de la página un anuncio convocando a un casting para asumir el rol de zombis y así conoció a algunos de los miembros del equipo.

Ahora, los eventos se estructuran en tres momentos: la preproducción, que involucra la concepción, planificación, coordinación con proveedores y miembros del staff y difusión; la producción, montaje o implementación de las actividades, y la postproducción, que incluye el desmontaje, cancelar los pagos y mostrar lo que fue la actividad en la red.

En el transcurso de los años han realizado eventos de inicio, mitad y final de temporada en grandes discotecas como Céntrica, ubicada en el Centro Cívico de Lima, y Mangos, situada en la avenida Arequipa. En ambas, la capacidad supera las 2000 personas. La entrada a estos eventos tiene un costo de alrededor de 15 soles y suele incluir un póster de la serie como obsequio. Durante ellos se sucede una serie de actividades que son planificadas con anterioridad: el tour del apocalipsis zombi, a un costo de 5 soles; maquillaje zombi, cuyo precio fluctúa entre 10 y 20 soles dependiendo del detalle de las cicatrices; fotos con walkers o elementos de la serie como Lucille, el arma de uno de los personajes, o Winslow, la cabeza con estacas de un walker; maratón de la temporada en HD; making of de los mejores capítulos de la temporada y otros materiales extras; concurso de cosplayer; feria walker, en la que se venden figuras de acción, cómics, pósters, cuadernos, tazas, calendarios y mochilas, entre otros materiales de merchandising; sorteos; soundtrack de la serie tocado en vivo, y otras actividades que han ido variando a lo largo del tiempo.

Una actividad que atrae mucho a los asistentes es la caracterización zombi. Esta consiste en maquillar con heridas, pústulas, cicatrices, impactos de bala, mordidas o rasguños creados con látex y pintura. La ruptura, lo desagradable, lo pútrido, la ropa más harapienta, el rastro de las heridas de lucha, normalmente asociados con la fealdad, es lo que llama la atención. En el limbo apocalíptico que enmarca la serie, lo feo y lo desagradable, al volverse rutinario, se acerca a la normalidad. Los protagonistas de la serie vienen a ser una suerte de antihéroes que en su esfuerzo por sobrevivir se tornan sucios, desarreglados, violentos y desequilibrados. Finalmente, su humanidad se desplaza hacia la no humanidad de los zombis, confundiéndolos. Así, lo bello, lo atractivo, lo bueno, lo agradable, o sea los atributos usualmente asociados a lo humano (a los sobrevivientes), se acercan a lo feo, lo malo, lo innoble, lo monstruoso, o sea a lo que la amenaza zombi simboliza. $Y$ esto es porque los sobrevivientes son virtualmente walkers, 
pues son portadores del virus, por eso por momentos su lucha se vuelve inocua, pero la esperanza reside en hallar una cura que pueda revertir la situación y preservar a la humanidad.

Los que hacen cosplay de los sobrevivientes juegan con esa perturbación de la normalidad. Transformados en zombis o en sobrevivientes, en los eventos los cosplayers se constituyen en modelos y, de esta manera, pasan de ser uno más entre los asistentes a convertirse en personajes que la gente reconoce. Esa notoriedad que ganan gracias al disfraz y al maquillaje es exacerbada por los flashes de quienes buscan tomarse fotos con ellos para luego compartirlas por los SNS.

Diana Taylor sostiene que las performances «funcionan como actos vitales de transferencia, transmitiendo saber social, memoria y sentido de identidad a través de acciones reiteradas» (2011, p. 20). En el caso de TWD-Perú, es posible recorrer a través de ellas los sentidos que viajan desde la serie de televisión para colgarse en la red y desprenderse en las actividades producidas por el grupo. Si bien los productos televisivos son cada vez más estandarizados y dirigidos a un consumo global que difunde ideas y valores morales, los miembros activos de TWD-Perú, al intervenirlos, los transforman y los vuelven propios adaptándolos a su experiencia vital. Debido a la interconexión ampliada por los SNS, han podido convertir su afición en un emprendimiento de producción cultural colaborativa (meta)mediática.

\section{EL DESPERTAR DEL EMPRENDIMIENTO FANDOM}

La participación de los públicos en el espacio transmedia podría explicarse a través del concepto del don, desarrollado por el antropólogo Marcel Mauss (2009). La teoría sobre la «economía del don» explica que el intercambio de regalos que se da sin un acuerdo explícito genera una obligación implícita que construye relaciones entre las personas. Es decir, se rige bajo el principio de reciprocidad. La remuneración por los bienes que se regalan es de orden social o intangible, como el prestigio, la estima, el establecimiento de relaciones, etc. Si extrapolamos esta teoría a TWD-Perú, las publicaciones que hacen impactan en miles de personas que los siguen en Facebook. Así, el trabajo de producción de contenidos es retribuido a través de los followers alcanzados, sus comments o likes, ya que esto les da notoriedad, pues la plataforma destaca lo que tiene mayor volumen de circulación. De esta manera, ser visto se convierte en el mayor capital de intercambio en esta economía. A mayor cantidad de likes en los sitios de relacionamiento social, mayores posibilidades de negociación. Los intercambios 
hacen que lo que se comparte a través de la página y también fuera de ella le dé prestigio al grupo. Desde otro punto de vista, los broadcasters suelen retribuir el trabajo de los fandoms con adelantos sobre lo que se viene, entradas a eventos o encuentros especiales con sus artistas favoritos.

Tradicionalmente el sistema de medios se rige bajo una lógica mercantil, es decir, sus producciones culturales obtienen un valor de orden económico, mientras que las creaciones de los fans solían guiarse por la economía del don, cuyos objetivos son de orden social. En el entorno mediático transmedia esta dicotomía se altera, porque para los medios se vuelve un imperativo lograr que el contenido original se comparta y para los públicos el compartir permite obtener beneficios económicos, ya no solo sociales. Esto se debe a que están despertando el interés comercial de los responsables de las series, directivos de las cadenas y publicistas. Así, los públicos, en especial los fandoms, son considerados como elementos clave dentro de la circulación de los productos culturales mediáticos, por lo que alcanzan mayor incidencia que antes, confundiendo la división entre la creación y la recepción.

Por consiguiente, la economía del don permite explicar solo parcialmente el modo en el que opera el intercambio entre fandoms en la actualidad, como el caso de TWD-Perú. Bajo este razonamiento, el trabajo de los fans es gratificante en un sentido básicamente social, pues las relaciones de intercambio que se dan entre ellos no implican una retribución monetaria.

Lawrence Lessig (2012) explica que la cultura de la red facilita una combinación entre una economía basada en el compartir y una economía comercial. Habla de una «tercera economía», híbrida, que para ser viable debe respetar los intereses de los participantes de uno y otro lado, de los que crean el material original y de los que remezclan y amplían su circulación.

A menudo los fandoms obtienen dinero por su trabajo, ya sea porque venden sus productos o servicios o porque la marca detrás de su afición se interesa por ellos para influir en más personas y difundir sus contenidos. De ahí que cada vez resulte menos adecuada la analogía del don para explicar el trabajo que hacen los fandoms en la era transmedia y sea necesario hablar de «economías híbridas», «múltiples» o de «economía fandom». En el caso que presento, así como en otros, los intercambios exceden los principios del don y se entremezclan también con la lógica comercial. Estos procesos basados en la producción cultural colaborativa son disruptivos, puesto que alteran esquemas y obligan a pensar en nuevas perspectivas sobre la propiedad y el consumo. 
Estas condiciones han llevado a que los fandoms sean más conscientes del valor que su compromiso genera en los intereses comerciales de la industria; a su vez, esta intenta premiar de diversas maneras la participación o se torna más permisiva con el uso de sus productos por aquellos. Conviene cuestionar quién usufructúa ese valor: si los fans o los productores. Si lo vemos desde la oferta, podría decirse que los productores se aprovechan la mano de obra de los aficionados para hacer circular sus materiales, pero si nos concentramos en el consumo se puede notar que ellos también sacan utilidad con sus prácticas. Al hacerlas no están pensando en beneficiar a los broadcasters ni en trabajar para ellos, sino en satisfacer y ampliar su propia experiencia. Por lo tanto, no hay una explotación de unos sobre otros sino un trato recíproco implícito en el que ambas partes buscan provecho. Como afirma Heather Horst (2012), las nuevas tecnologías alteran las nociones de propiedad.

TWD-Perú no ha tenido inconvenientes en cuanto a los derechos por el uso de la imagen de la serie. Incluso Vuk Editores, la empresa que tiene los derechos de reproducción del cómic en nuestro país, participa en los eventos organizados por ellos. En uno de los eventos en los que participaron como invitados, un representante de Fox en el Perú se les acercó indagando qué hacían y qué planes tenían, pero no tuvo mayores efectos.

Nos hemos juntado con gente de Fox Latinoamérica que vieron nuestro movimiento y les pareció chévere. Ellos se nos acercaron en el primer Popcorn Festival [2014]. Pero después de una reunión nos dimos cuenta de que en realidad no había cómo hacer sinergia. Nosotros funcionamos tranquilamente, y cualquier material que necesitamos, lo obtenemos. Tenemos contacto con los showrunners de AMC. Alguna vez se pensó hacer un lanzamiento de temporada en conjunto con los de Fox, pero no hubo una correcta coordinación. Aún está en proyecto, quizá más adelante se dé (Mario Maldonado).

Si las creaciones culturales de los fandoms contribuyen con la circulación de los contenidos y guardan cierta fidelidad con el original, la industria no bloquea $o$ impide su actividad porque el fandom mantiene viva la marca, hace que su valor crezca o se sostenga. Precisamente, el trabajo que hacen estos grupos permite rentabilizar las creaciones culturales de los medios. Por su lado, los miembros activos de TWD-Perú prefieren conservar su independencia, porque parte de su identidad implica explicar, desarrollar, criticar el producto que les ofrecen, y para ello es necesario mantener cierta distancia. En una oportunidad le pregunté al community manager si le gustaría oficializar la página de TWD-Perú, a lo que respondió con una negativa argumentando que eso limitaría la libertad para colocar 
el contenido que les plazca, no solo de la serie sino de temas afines. Tampoco les permitiría compartir fotos de detrás de cámaras que no sean oficiales ni crear y desarrollar eventos. «El no ser oficiales nos da libertad, no nos frena, podemos criticar y hacer lo que nos parece» (Jonathan Aguilar).

En general, los fandoms constituyen un apocalipsis para el sistema de medios masivos, que aún exhala ahogado cuando de mantener el control sobre sus marcas se trata. A partir de su afición se constituyen en pequeños emprendedores/ productores cuyo pretexto puede ser una serie de televisión, pero que desborda la pantalla y los límites del mercado oficial para crear un circuito paralelo que resulta una extensión del mercado mediático cambiante. Este ya no se basa solo en la distribución de contenidos de las grandes empresas de broadcast hacia las audiencias, sino que los fandoms comparten y (re)crean el material original de manera imprevisible.

El emprendimiento que desarrolla TWD-Perú nace a partir del interés común por una trama mediática, pero no tiene una relación directa con el medio más allá del germen que lo impulsa. Representa una entrada al sistema por la puerta trasera, porque al medio le conviene que la circulación de su producto se expanda a través de las prácticas de aquellos. En el contexto transmedia surge una oportunidad que algunos han aprovechado para generarse recursos gracias a un emprendimiento alterno y apasionado, como es el caso del administrador de la página TWD-Perú y quienes lo apoyan:

Al comienzo, cuando mi mamá me veía metido en la página, me criticaba «cómo iba a darlo todo por la página», pero cuando vio que me generaba un ingreso me decía «oe, hijito, cuándo tienes otro tour». Ahora mi mamá está también metida en los eventos. Mis amigos me decían que estaba loco y ahora me dicen «llámame, pues». Ellos a veces me ayudan a desarmar todo, llevarlo a la cochera, al camión y de ahí a mi casa [...] Para mí esto de TWD ha cambiado todo. He creado el tour, he hecho eventos y me ha ayudado bastante, la verdad, porque eso me genera un ingreso que me permite mantener la página con más actividad para los fans y para mí, porque la verdad son cosas que me gustan (Jonathan Aguilar).

Las performances que realiza TWD-Perú funcionan como un emprendimiento que posibilita que los miembros obtengan notoriedad, conocimientos en creación de contenidos, liderazgo, marketing digital, organización de eventos, producción de contenidos, administración, así como una forma de generarse recursos. El discurso de la serie adquiere significado en tanto simboliza su búsqueda de superación constante. Para que el emprendimiento de este grupo se haya podido 
mantener en el tiempo, ha requerido perseverancia, creatividad, interacción y ampliación de sus redes sociales, lo que les ha permitido hacer frente a diversos obstáculos. Se han convertido en líderes-emprendedores que gestionan su afición, y al hacerlo, crean un valor adicional al texto mediático original.

Una característica fundamental de TWD-Perú es que no solo produce contenidos que intercambia en la red, sino que con el tiempo se ha convertido en un pequeño negocio. Por más que los miembros activos del fandom afirman que su principal objetivo no es lucrar, sino compartir una afición y una emoción común por la serie, a medida que han ido creciendo, recuperar la inversión y obtener una ganancia se ha convertido en algo importante. A grandes rasgos, para un evento invierten alrededor de 8000 soles y, si resulta exitoso, pueden tener ingresos por más del doble de esta cifra.

Su afición les ha permitido empoderarse y desarrollar un emprendimiento basado en la extensión de la serie TWD. Cabe resaltar que, en general, las actividades en las que los fandoms se comprometen no necesariamente les proveen una recompensa económica inmediata, pero son una forma de construir un branding personal, de hacerse conocidos, lo que a la larga puede desembocar en un beneficio monetario. Es una inversión cuya remuneración se va dando de a pocos, con perseverancia y actividad constante para lograr el imperativo de los SNS: hacerse visibles. Ciertamente, si no obtienes seguidores y vistas no destacas en las redes, e incluso el mismo espacio te invisibiliza. Por el contrario, si alcanzas a miles de personas, la plataforma te visibiliza y llamas la atención de las marcas.

En esta «economía fandom», si no se está constantemente performando, se corre el riesgo de desaparecer. Uno de los imperativos para la sobrevivencia en la trama apocalíptica es estar en constante movimiento y dicha premisa es también una norma dentro de TWD-Perú (y en general en la cultura transmedia), pues ellos reconocen que si no hacen eventos y desarrollan actividades para los fans el grupo corre el riesgo de desaparecer. Por eso, mantienen actividad constante, de lo contrario no obtienen notoriedad y eso es sinónimo de no-existencia, de muerte, pero esta no es una muerte física sino una muerte virtual como la de los zombis, valga la analogía. Parafraseando a Henry Jenkins, «si no se propaga, muere». En su libro Spreadable Media (2013), Jenkins aborda la multiplicidad de formas en las que circula el contenido hoy en día, ya no solo de manera unidireccional, en la que un grupo reducido de productores crea contenidos para audiencias masivas, sino que en el escenario mediático emergente la circulación es multidireccional. Se mezcla la circulación de arriba hacia abajo y viceversa de una manera más participativa y a su vez confusa. 
Lo que TWD-Perú hace con los productos mediáticos se vincula con el consumo, la producción a partir de una narrativa mediática y un tipo de trabajo alternativo que no está plenamente integrado a la industria, aunque cada vez llama más la atención de esta. Los miembros han aprovechado los medios digitales para poder desarrollar un emprendimiento. Su afición les ha valido un lugar en el mercado de la creación de contenidos y ha motivado su interacción con personas diversas, no solo fans. Han desarrollado eventos, puestas en escena y alianzas estratégicas con productores/empresarios y con otros fandoms. Han viajado para hacer sus eventos a las provincias de Arequipa, Trujillo, Ayacucho y Huancayo. Además, han colaborado en actividades convocadas por diversas empresas.

La revelación que nos trae este apocalipsis mediático por medio del emprendimiento de TWD-Perú es por un lado, la permeabilidad entre el tiempo libre o de ocio y el tiempo laboral, ya que su actividad recreativa se convierte en un quehacer, pero uno que realizan a voluntad y con pasión; por otro lado, la descentralización de la creación y circulación de nuevos contenidos basados en un producto mediático precedente, y finalmente, la generación de recursos bajo una racionalidad económica hasta ahora alternativa y que abre las puertas a la creatividad individual y colectiva.

\section{REFERENCIAS BIBLIOGRÁFICAS}

Booth, Paul (2010). Digital Fandom. New media studies. Nueva York: Peter Lang Publishing.

Christakis, Nicholas y James Fowler (2010). Conectados. El sorprendente poder de las redes sociales y cómo nos afectan. México: Taurus.

Dayan, Daniel (2005). Mothers, midwives and abortionists: Genealogy, obstetrics, audiences and publics. En Sonia Livingstone (ed.), Audiences and publics. When culture engagement matters for the public sphere (pp. 43-76). Bristol: Intellect.

Horst, Heather A. y Daniel Miller (eds.) (2012). Digital Anthropology. Londres: Berg.

Jenkins, Henry (2008). La cultura de la convergencia de los medios de comunicación. Barcelona: Paidós.

Jenkins, Henry (2010). Piratas de textos. Fans, cultura participativa y televisión. Barcelona: Paidós.

Jenkins, Henry, Sam Ford y Joshua Green (2013). Spreadable media. Creating value and meaning in the networking culture. Nueva York: New York University Press. 
Lessig, Lawrence (2012). Remix: cultura de la remezcla y derechos de autor en el entorno digital. Barcelona: Icaria.

Lipovetsky, Gilles (2007). La felicidad paradójica. Barcelona: Anagrama.

Lipovetsky, Gilles y Charles Sébastien (2014). Los tiempos hipermodernos. Barcelona: Anagrama.

Maffesoli, Michel (2004). El tiempo de las tribus. El declive del individualismo en las sociedades de masas. Barcelona: Icaria.

Mauss, Marcel (2009). Ensayo sobre el don. Forma y función del intercambio en las sociedades arcaicas. Buenos Aires: Katz Editores.

Pink, Sarah, Heather Horst, John Postill, Larissa Hjorth y Tania Lewis (2015). Digital Ethnography. Principles and Practice. Los Angeles: Sage.

Sandvoss, Cornel (2005). Fans: The mirror of consumption. Cambridge: Polity Press.

Sandvoss, Cornel, Jonathan Gray y C. Lee Harrington (2017). Fandom. Identities and communities in a mediated world. Nueva York: New York University Press.

Siegel, Lee (2008). El mundo a través de la pantalla. Ser humano en la era de la multitud digital. Barcelona: Aibana.

Stein, Louisa Ellen (2015). Millennial Fandom. Television audiences in the transmedia age. Iowa City: University of Iowa Press. https://doi.org/10.2307/j.ctt20p587m

Lévy-Strauss, Claude (2015). Todos somos caníbales. Buenos Aires: Libros del Zorzal.

Sullivan, John L. (2013). Media Fandom and Audience Subcultures. En Media Audiences. Effects, Users, Institutions, and Power (pp. 189-212). Thousand Oaks, CA: Sage.

Taylor, Diana y Marcela Fuentes (2011). Estudios avanzados de performance. México: Fondo de Cultura Económica.

Toffler, Alvin (1995). La tercera ola. Buenos Aires: Plaza \& Janés. 